\title{
Short communication: Effects of lysolecithin on milk fat synthesis and milk fatty acid profile of cows fed diets differing in fiber and unsaturated fatty acid concentration
}

\author{
D. E. Rico, ${ }^{*}$ Y. Ying, $\dagger^{1}$ and K. J. Harvatine $\dagger^{2}$ \\ *Centre de Recherche en Sciences Animales à Deschambault (CRSAD), Deschambault, QC, Canada, G0A 1S0 \\ †Department of Animal Science, Penn State University, University Park 16802
}

\begin{abstract}
Thirteen multiparous Holstein cows were used in a crossover design that tested the effect of lysolecithin in diets differing in neutral detergent fiber (NDF) and unsaturated fatty acid (FA) concentrations. Experimental periods were $20 \mathrm{~d}$ in length and included two 10-d phases. A standard fiber and lower fat diet was fed the first $10 \mathrm{~d}(30.5 \% \mathrm{NDF}$, no added oil, lower-risk phase) and a lower NDF and higher oil diet was fed during the second $10 \mathrm{~d}(29.0 \% \mathrm{NDF}$ and $2 \%$ oil from whole soybeans and soybean oil, high-risk phase). Treatments were control and $10 \mathrm{~g} / \mathrm{d}$ of lysolecithin (LYSO) extended in a ground corn carrier. Milk was sampled on d 0,5, and 10 of each phase for determination of fat and protein concentration and FA profile. We found no effect of treatment or treatment by time interaction for dry matter intake, milk yield, or milk protein concentration. A treatment by time interaction was observed for milk fat concentration and yield. Milk fat concentration was higher in LYSO on d 5 of the lower-risk phase, but decreased progressively in both treatments during the high-risk phase. Milk fat yield was not different among treatments during the lower-risk phase, but was lower in LYSO on d 15 and tended to be lower on d 20 during the high-risk phase. Concentrations of milk de novo FA decreased and preformed FA increased during the high-risk phase, but we found no effect of treatment or treatment by time interactions. We noted an effect of time, but no treatment or treatment by time interactions for milk trans FA isomers. Briefly, trans-11 C18:1 and cis-9,trans-11 conjugated linoleic acid progressively decreased as trans-10 C18:1 and trans-10,cis-12 conjugated linoleic acid progressively increased during the high-risk phase. The LYSO increased milk fat concentration when feeding a higher fiber and lower
\end{abstract}

Received April 2, 2017.

Accepted July 17, 2017.

${ }^{1}$ Current address: Department of Medicine, Penn Center for Pulmonary Biology, Penn Cardiovascular Institute, University of Pennsylvania, Philadelphia, PA 19104.

${ }^{2}$ Corresponding author: kjh182@psu.edu unsaturated FA diet, but decreased milk fat yield when feeding a lower fiber and higher unsaturated FA diet, although biohydrogenation pathways and capacity did not appear to be modified. The effect of lysolecithin on rumen fermentation warrants further investigation, but is not recommended when feeding lower fiber and higher unsaturated fat diets.

Key words: emulsifier, lysolecithin, milk fat, biohydrogenation

\section{Short Communication}

Biohydrogenation (BH)-induced milk fat depression (MFD) is a specific reduction in milk fat yield, with no concurrent change in milk or milk protein yield, commonly observed in cows fed low-fiber or high-UFA diets (Bauman and Griinari, 2001). These factors cause alterations in the ruminal BH pathway of UFA, resulting in increased production of bioactive $\mathrm{BH}$ intermediates such as trans-10,cis-12 CLA, which are potent inhibitors of mammary lipid synthesis (Bauman and Griinari, 2001). Following dietary modifications, alternate biohydrogenation pathways and MFD can be observed within 7 to $10 \mathrm{~d}$ (Shingfield et al., 2006, Rico and Harvatine, 2013) and are closely associated with modifications in the ruminal microbial population (Weimer et al., 2010, Azad et al., 2015, Rico et al., 2015).

Emulsifiers are amphiphilic substances capable of mixing lipids and water. Dietary inclusion of an emulsifier, such as Tween 80, has been shown to increase enzymatic activity (Lee and Ha, 2003, Kim et al., 2004), enhance VFA production (Chen et al., 2011), and increase the digestibility of fiber and of other nutrients (Kim et al., 2004) in in vitro fermentation systems.

Lysolecithin is a very potent emulsifier derived from enzymatic hydrolysis of lecithin. It is naturally produced in the small intestine of the cow through phospholipase A2 hydrolysis of lecithin and aids in digestion of fatty acids (FA); it is also produced to a lesser extent in the rumen from degradation of feed phospholipids, but is also degraded by rumen microorganisms (Dawson, 1959). Importantly, lysolecithin has been shown 
to improve feed efficiency and growth in nonruminants (Schwarzer and Adams, 1996), presumably through improved digesta emulsification or modification of gut physiology (Brautigan et al., 2017). Lysolecithin has the potential to affect rumen fermentation as an emulsifier; for example, by increasing substrate-enzyme interaction. Furthermore, an interaction with dietary fat is expected, as lysolecithin is expected to increase emulsification of FA, making them more available for biohydrogenation as well as increase their passage through association with the liquid phase.

Our objective was to investigate the effect of lysolecithin in diets with lower and higher risk for BHinduced MFD (i.e., diets differing in PUFA and fiber). We hypothesized that lysolecithin would reduce the occurrence and extent of MFD and associated $\mathrm{BH}$ intermediates when feeding diets with increasing risk of MFD by increasing FA emulsification and increasing $\mathrm{BH}$ and passage rates.

Thirteen noncannulated, postpeak (132 \pm 42 DIM; mean $\pm \mathrm{SD}$ ) multiparous Holstein cows from the Pennsylvania State University Dairy Research Center were used. All experimental procedures were approved by the Pennsylvania State University Institutional Animal Care and Use Committee. Cows were randomly assigned to treatment sequences in a crossover design that tested increasing 2 levels of UFA and NDF during 2 experimental phases. The first $10 \mathrm{~d}$, a higher-fiber and lower-UFA diet was fed $30.5 \%$ NDF, no added oil, lower-risk phase); the second $10 \mathrm{~d}$, a lower-NDF and higher-UFA diet was fed $(29 \% \mathrm{NDF}$ and $2 \%$ oil from whole soybeans and soybean oil, high-risk phase). A 14-d washout period allowed recovery of normal ruminal $\mathrm{BH}$ and milk fat yield between experimental periods. Treatments were control and lysolecithin (LYSO; $10 \mathrm{~g} / \mathrm{d}$ per cow of lysolecithin from Lysoforte, Kemin Industries, Des Moines, IA). Lysolecithin was extended in a ground corn carrier and added in a small batch vertical TMR mixer. We were not aware of previous work with lysolecithin in ruminants, so the dose was based on work in nonruminants (e.g., Schwarzer and Adams, 1996; Melegy et al., 2010). The control diet was fed for $7 \mathrm{~d}$ before initiation of the experiment. Cows were fed once daily at $110 \%$ of expected intake and milked twice daily in a milking parlor. Milk yield was measured by an integrated milk meter (AfiMilk, SAE Afikim, Afikim, Israel). The parlor stalls were calibrated weekly using data from the entire herd $(>200$ cows) over $7 \mathrm{~d}$. Stall adjustments were determined by modeling the effect of day, milking (a.m./p.m.), cow, and stall, excluding observations of experimental cows during treatment periods. Milk was sampled the day before the start of the experiment, at the end of the washout period, and d 5 and 10 of each dietary phase.
All milk samples were analyzed for fat and true protein by infrared spectroscopy by Dairy One (State College, PA). Additionally, samples were composited within day by milk yield before determination of FA profile by GC, as described by Rico and Harvatine (2013). Briefly, milk triglycerides were extracted in hexane:isopropanol and then base-methylated. The temporal interaction of lysolecithin and dietary risk factors was analyzed using the repeated measures statement of PROC MIXED (version 9.3, SAS Institute Inc., Cary, NC). The model included the random effect of sequence, cow nested in sequence, and period, and the fixed effects of treatment, time, and their interaction. The autoregressive $[\operatorname{AR}(1)]$ or heterogeneous autoregressive $[\mathrm{ARH}(1)]$ covariance structures were used depending on model fit based on the Schwarz Bayesian criterion. Preplanned contrast tested the effect of treatment at each time point.

Experimental diets contained corn silage, mixture of grass hay and straw, ground corn, canola meal, cottonseed hulls, roasted soybeans, encapsulated urea, and a vitamin and mineral supplement (Supplemental Table S1; https://doi.org/10.3168/jds.2017-12976). The diet fed during the high-risk phase contained an additional 1.5 percentage units of whole soybeans and 1.3 percentage units of soybean oil and was 1.5 percentage units lower in NDF. Consequently, total FA and C18:2 n-6 content were increased by 44 and $66 \%$ compared with the low-risk phase, respectively. The lower-risk diet contained $17.6 \% \mathrm{CP}, 30.5 \% \mathrm{NDF}, 28.6 \%$ starch, and $3.45 \%$ total FA, and the high-risk diet contained $17.8 \%$ CP, $29.0 \%$ NDF, $29.3 \%$ starch, and $4.98 \%$ total FA. As expected, the reduction in NDF while increasing oil content in the high-risk ration resulted in induction of modest BH-induced MFD. Briefly, a progressive decrease in milk fat concentration and yield occurred in both treatments during the high-risk phase, although it was more pronounced for the LYSO treatment. This coincided with a reduction in the proportions of de novo and 16C FA, whereas preformed FA concentration increased. Additionally, intermediates of the normal pathway of $\mathrm{BH}$ (trans-11 C18:1 and cis-9,trans-11 CLA) peaked on d 15 during the high-risk phase and the concentrations of $\mathrm{FA}$ in the alternate $\mathrm{BH}$ pathway (trans-10 C18: and trans-10,cis-12 CLA) progressively increased in both treatments, similar to the shift in $\mathrm{BH}$ pathways during BH-induced MFD previously reported (Shingfield et al., 2006; Rico and Harvatine, 2013).

We observed no effect of treatment or treatment by time interaction on DMI or milk yield, but a treatment by time interaction occurred for milk fat yield and concentration (Figure 1). Milk fat concentration was higher in LYSO than in control on d 5 during the low-risk phase, but milk fat yield was not different. Milk fat yield was lower in LYSO on d 15 and tended 
A. DMI

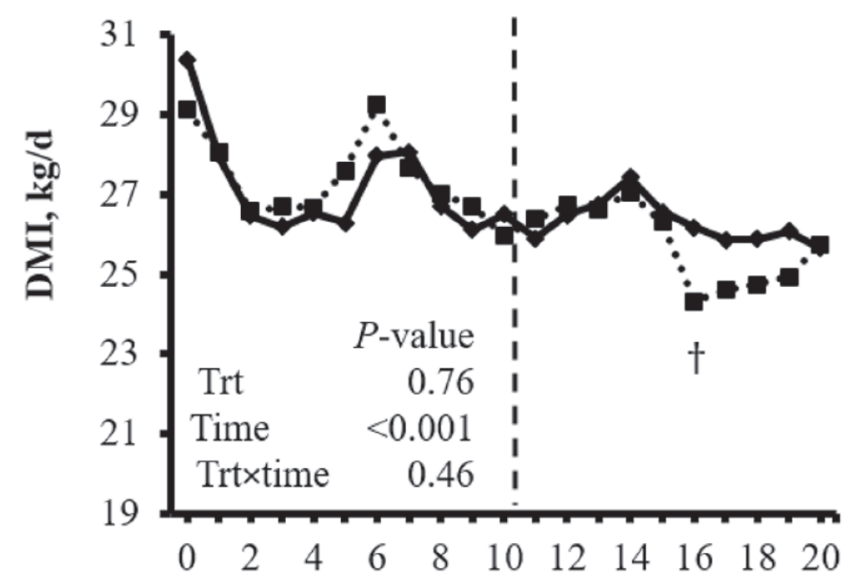

C. Fat Yield

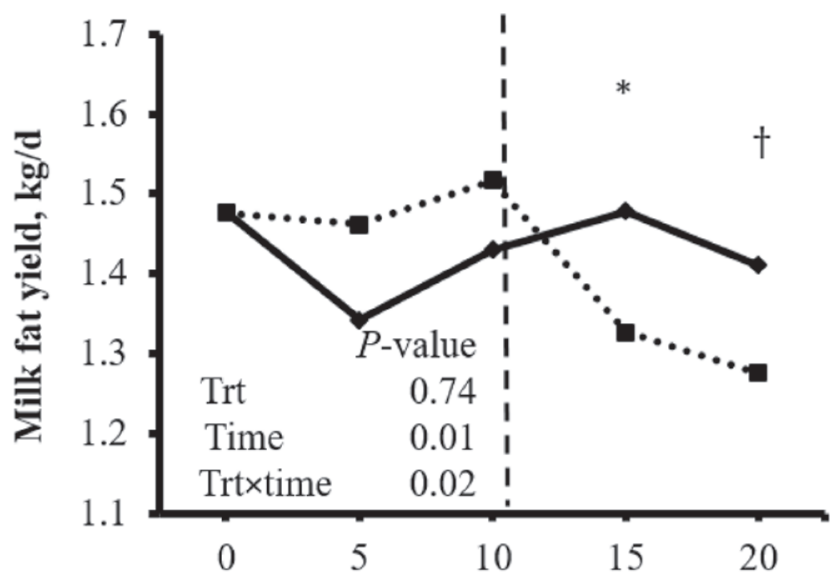

\section{E. Protein Yield}

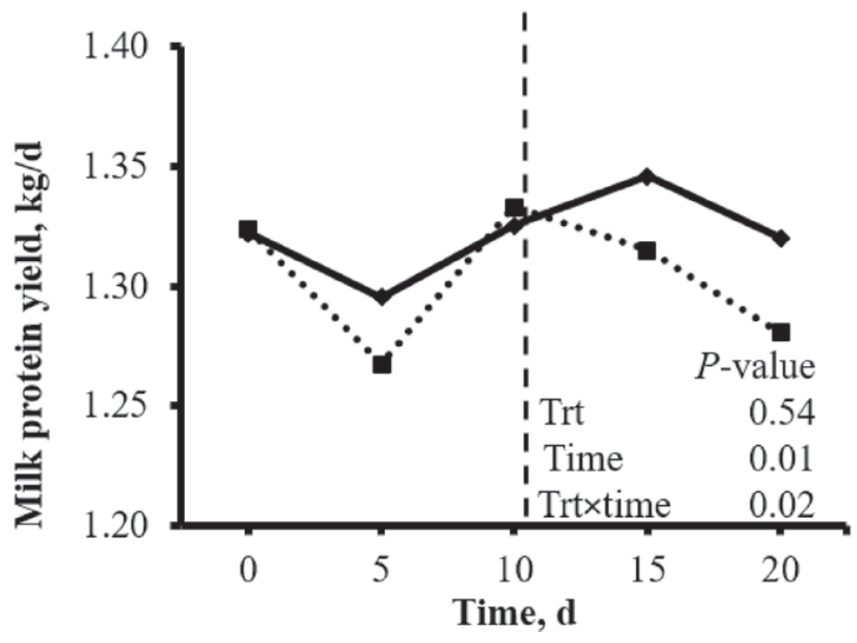

\section{B. Milk Yield}

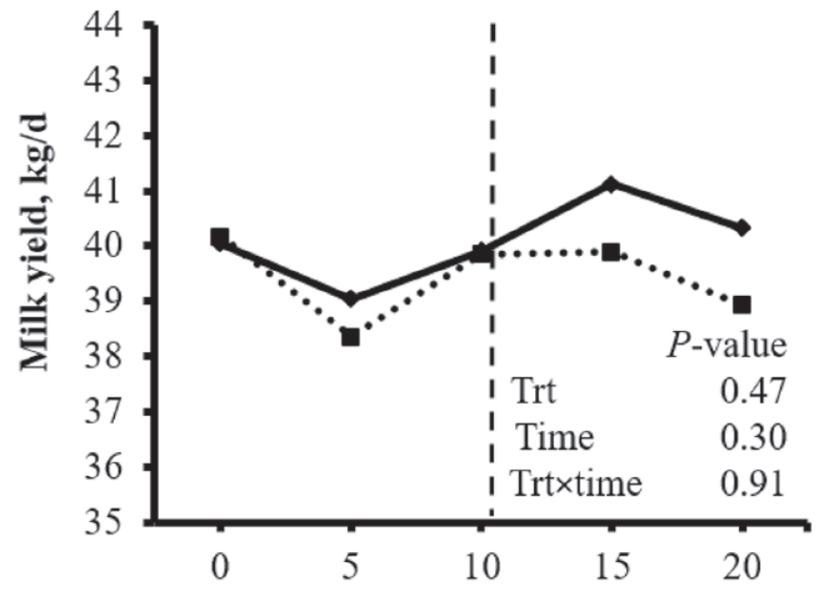

\section{Fat percent}

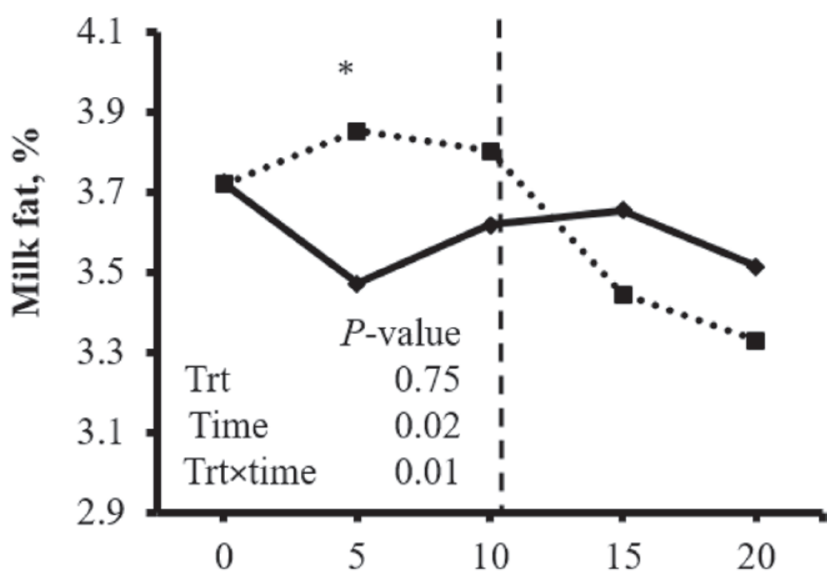

\section{F. Protein percent}

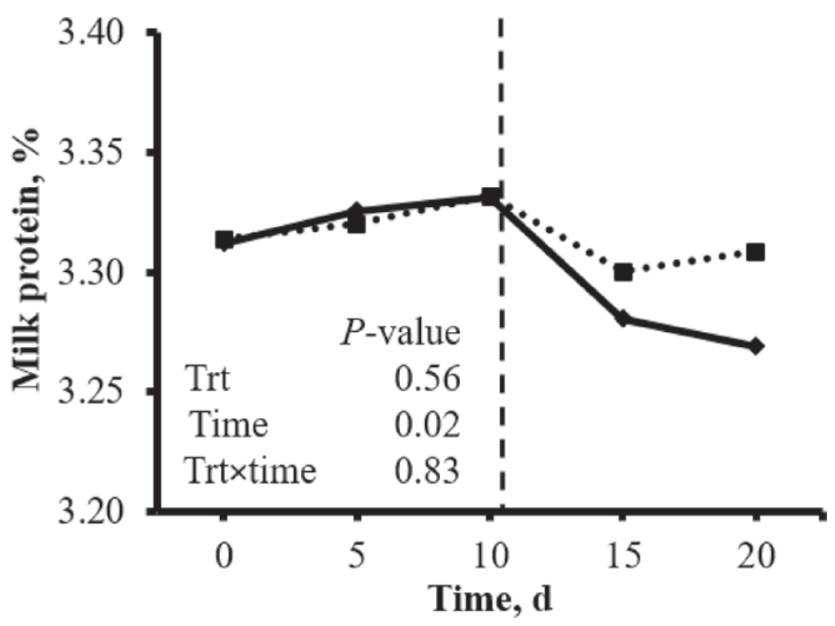

Figure 1. Effect of lysolecithin on intake and milk yield and composition. Control = no lysolecithin; LYSO = lysolecithin fed $10 \mathrm{~g} / \mathrm{cow}$ per day; Trt $=$ main effect of treatment; Time $=$ main effect of day in treatment; Trt $\times$ time $=$ interaction of treatment and time. The dashed line represents the transition from the lower- to the higher-risk phase. ${ }^{*} P<0.05, \dagger P<0.10$. 
$\rightarrow$ Control

..-.. LYSO

A. de novo FA \%

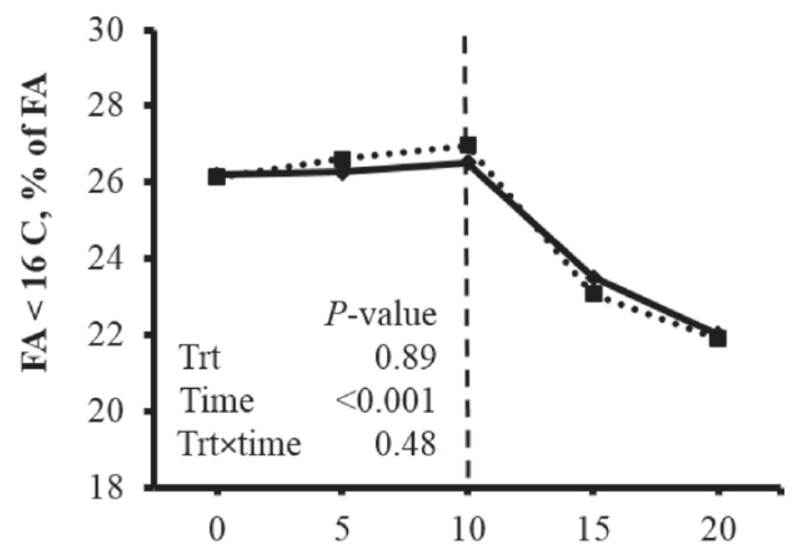

C. 16 C FA \%

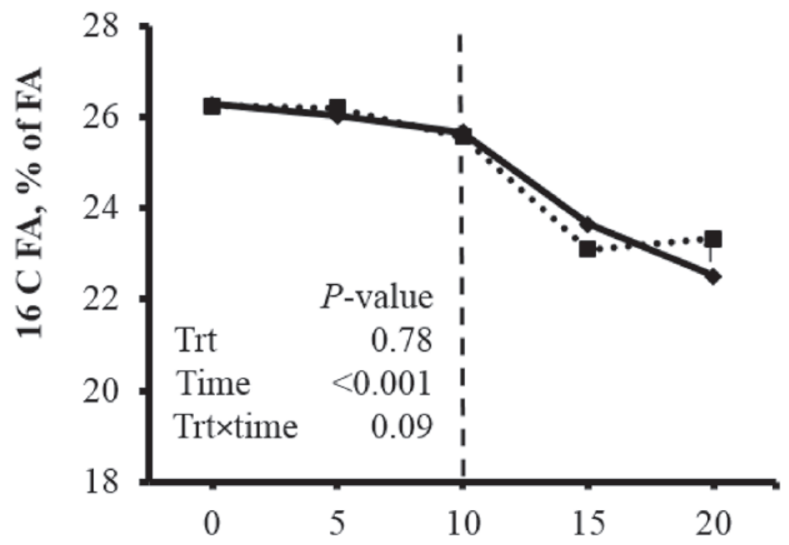

D. Preformed FA \%

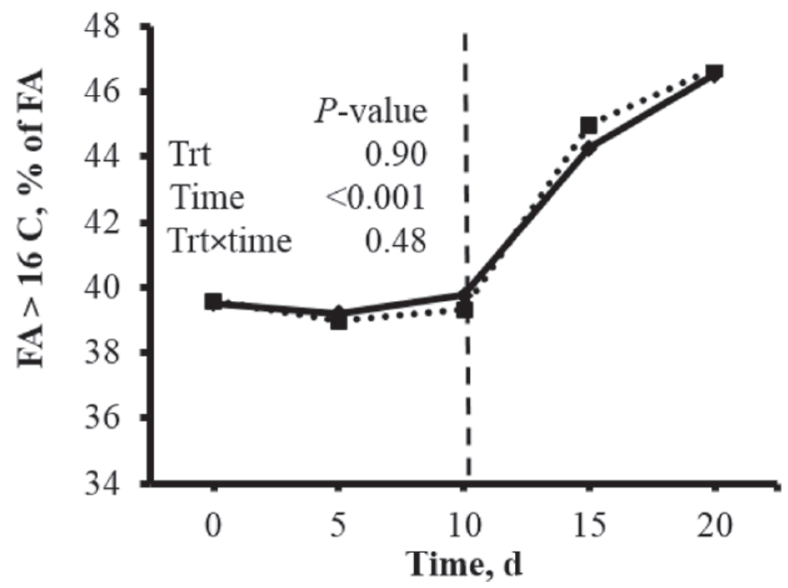

B. de novo FA yield



D. 16 C FA yield



E. Preformed FA yield



Figure 2. Effect of lysolecithin on milk fatty acids (FA) by source. Control = no lysolecithin; LYSO = lysolecithin fed $10 \mathrm{~g} / \mathrm{cow}$ per day; Trt $=$ main effect of treatment; Time $=$ main effect of day in treatment; Trt $\times$ time $=$ interaction of treatment and time. Fatty acids $<16 \mathrm{C}$ originate from de novo synthesis in the mammary gland; fatty acids $>16 \mathrm{C}$ originate from plasma; $16 \mathrm{C}$ fatty acid originate from both sources. The dashed line represents the transition from the lower- to the higher-risk phase. ${ }^{*} P<0.05, \dagger P<0.10$. 


\section{A. trans-10 C18:1}



C. trans-10, cis-12 CLA

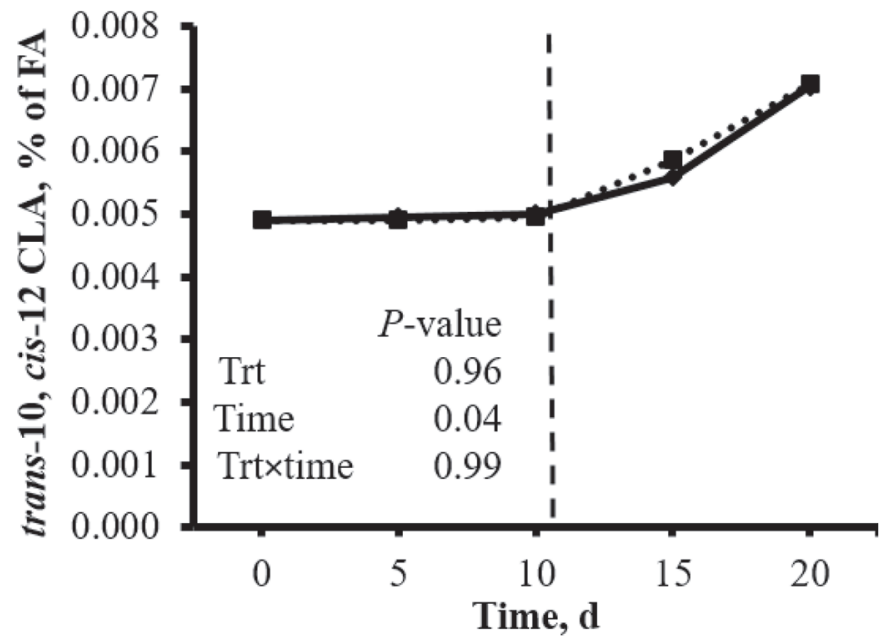

$\rightarrow$ Control

$\cdot \cdot \cdot \cdot$ LYSO

\section{B. trans-11 C18:1}

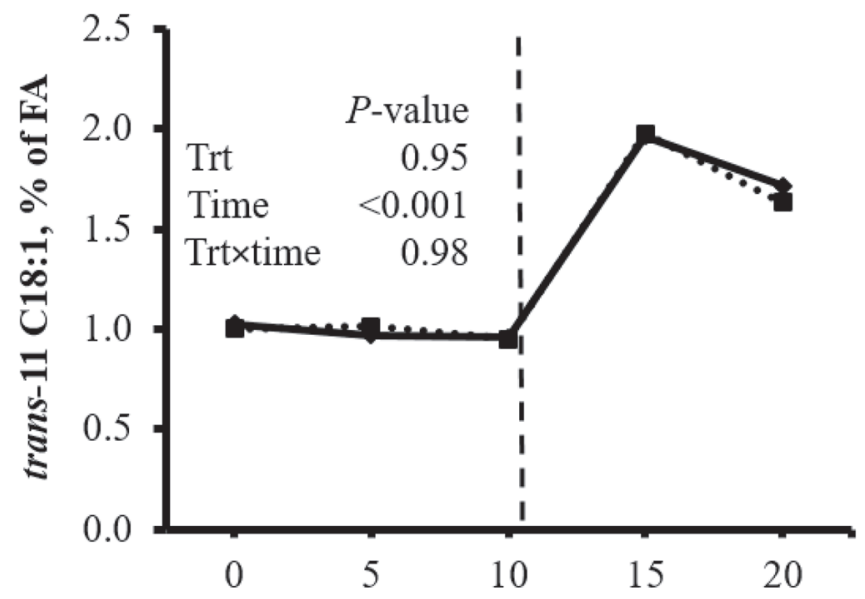

D. cis-9,trans-11 CLA

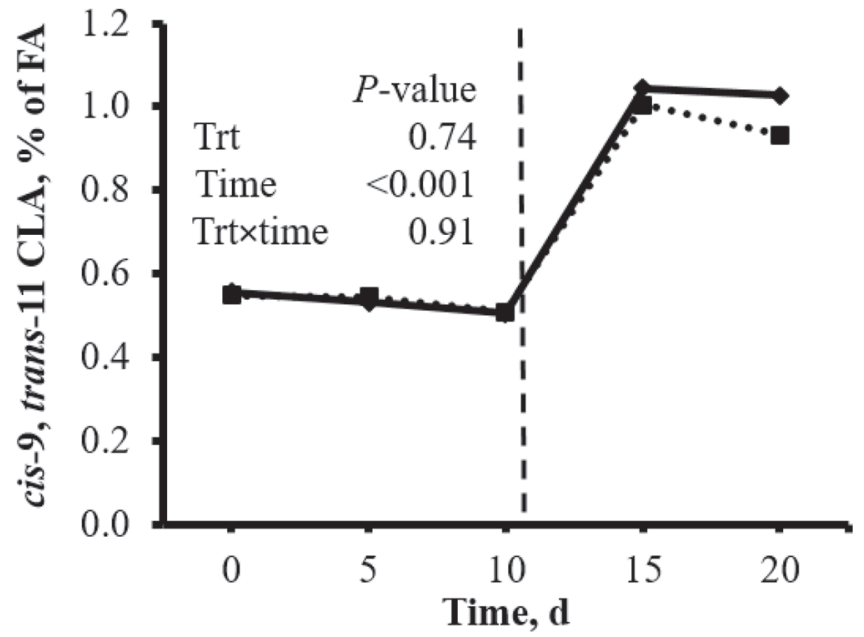

Figure 3. Effect of lysolecithin on milk select trans fatty acids. Control = no lysolecithin; LYSO $=$ lysolecithin fed 10 g/cow per day; Trt $=$ main effect of treatment; Time $=$ main effect of day in treatment; Trt $\times$ time $=$ interaction of treatment and time. The dashed line represents the transition from the lower- to the higher-risk phase.

to be lower on d 20 during the high-risk phase. Interestingly, no differences between treatments were observed in altered $\mathrm{BH}$ intermediates (e.g., trans-10 C18:1 and trans-10, cis-12 CLA) during the lower-risk phase (Figures 2 and 3), suggesting that the increase in milk fat concentration was not due to differences in $\mathrm{BH}$-induced MFD.

We recently observed that acetate infusion dosedependently increased milk fat yield in the absence of BH-induced MFD (Urrutia and Harvatine, 2017). Jenkins (1990) reported that commercial lecithin, a phospholipid obtained from oil degumming with mod- est emulsifier properties (Scholfield, 1981), decreased ruminal acetate and acetate-to-propionate ratio less than hydrogenated fat, but did not change total-tract digestibility. Abel-Caines et al. (1998) reported that a mixture of lecithin and soapstock increased acetateto-propionate ratio in continuous culture fermenters compared with soybean oil. However, lecithin fed at $5.2 \%$ of the diet decreased ruminal fiber, OM digestibility, and ruminal acetate similar to corn oil in sheep, suggesting ruminal activity of UFA in phospholipids similar to that of other UFA when fed at higher rates (Jenkins et al., 1989). The lecithin also increased ether 
extract digestibility, and the authors proposed that although extensive hydrolysis of lecithin was expected to occur in the rumen, enough may have escaped to assist FA digestibility in the intestine (Jenkins et al., 1989). In the current experiment, the increase in milk fat concentration during the lower-risk phase may be due to increased acetate supply, which agrees with a tendency for increased secretion of de novo FA in the lysolecithin treatment, although additional measures of fiber digestibility were not made.

Additionally, the lack of differences in BH intermediates between the 2 treatments suggests that the reduction in milk fat yield, observed in LYSO during the high-risk phase, is not related to classical BH-induced MFD, but could perhaps be associated with the numerically lower milk yield in that treatment during the high-risk phase. Under the dietary conditions evaluated in the present study, lysolecithin had no effects on the $\mathrm{BH}$ intermediates related to milk fat depression; however, differences in milk fat synthesis were detected and were dependent on the NDF and UFA content of the diet. Abel-Caines et al. (1998) reported lecithin feeding at $2.25 \%$ of DM resulted in increased linoleic acid (C18:2 n-6) concentrations in milk fat, suggesting partial protection from ruminal degradation, which would be expected to decrease the risk of BH-induced MFD. It is possible that emulsifiers may increase FA passage with the liquid phase, inhibit hydrolysis, or biohydrogenation rate. However, no difference in linoleic, $\alpha$-linolenic, or stearic acid were observed in milk in the current experiment (Supplemental Figure S1; https:// doi.org/10.3168/jds.2017-12976).

In conclusion, lysolecithin may be advantageous to increase milk fat when feeding a higher-fiber and lowerfat diet, but not when feeding lower NDF and higher levels of unsaturated fat. The mechanism by which lysolecithin could modulate rumen fermentation and milk fat is not clear, but may include emulsification of substrate in the rumen or intestines and warrants further mechanistic investigation.

\section{ACKNOWLEDGMENTS}

We gratefully acknowledge Kemin Industries (Des Moines, IA) for supplying the lysolecithin and Ken Griswold (Kemin) for insightful discussion. We also recognize Natalie Urrutia, Mutian Niu, and Liying Ma at Penn State University for technical assistance.

\section{REFERENCES}

Abel-Caines, S. F., R. J. Grant, and M. Morrison. 1998. Effect of soybean hulls, soy lecithin, and soapstock mixtures on ruminal fermentation and milk composition in dairy cows. J. Dairy Sci. 81:462-470.

Azad, E., D. E. Rico, H. Derakhshani, K. J. Harvatine, and E. Khafipour. 2015. Composition of rumen microbiota alters following dietinduced milk fat depression in dairy cows. J. Dairy Sci. 98(ESuppl. 2):140.

Bauman, D. E., and J. M. Griinari. 2001. Regulation and nutritional manipulation of milk fat: Low-fat milk syndrome. Livest. Prod. Sci. 70:15-29.

Brautigan, D. L., R. Li, E. Kubicka, S. D. Turner, J. S. Garcia, M. L. Weintraut, and E. A. Wong. 2017. Lysolecithin as feed addtive enhances collagen expression and villus length in the jejunum of broiler chickens. Poult. Sci. In press.

Chen, Y., H. Zhang, H. Wang, and K. Yang. 2011. Effects of dietary addition of non-ionic surfactants on ruminal metabolism and nutrient digestion of Chinese merino sheep. Asian J. Anim. Vet. Adv. 6:688-696.

Dawson, R. M. C. 1959. Hydrolysis of lecithin and lyso-lecithin by rumen microorganisms of the sheep. Nature 183:1822-1823.

Jenkins, T. C. 1990. Nutrient digestion, ruminal fermentation, and plasma lipids in steers fed combinations of hydrogenated fat and lecithin. J. Dairy Sci. 73:2934-2939.

Jenkins, T. C., T. Gimenez, and D. L. Cross. 1989. Influence of phospholipids on ruminal fermentation in vitro and on nutrient digestion and serum lipids in sheep. J. Anim. Sci. 67:529-537.

Kim, C.-H., J. N. Kim, J. K. Ha, S. G. Yun, and S. S. Lee. 2004. Effects of dietary addition of surfactant tween 80 on ruminal fermentation and nutrient digestibility of Hanwoo steers. Asian-australas. J. Anim. Sci. 17:337-342.

Lee, S. S., and J. K. Ha. 2003. Influences of surfactant tween 80 on the gas production, cellulose digestion and enzyme activities by mixed rumen microorganisms. Asian-australas. J. Anim. Sci. 16:11511157.

Melegy, T., N. F. Khaled, R. El-Bana, and H. Abdellatif. 2010. Dietary fortification of a natural biosurfactant lysolecithin in broiler. Afr. J. Agric. Res. 5:2886-2892.

Rico, D. E., and K. J. Harvatine. 2013. Induction of and recovery from milk fat depression occurs progressively in dairy cows switched between diets that differ in fiber and oil concentration. J. Dairy Sci. 96:6621-6630.

Rico, D. E., S. H. Preston, J. M. Risser, and K. J. Harvatine. 2015. Rapid changes in key ruminal microbial populations during the induction of and recovery from diet-induced milk fat depression in dairy cows. Br. J. Nutr. 114:358-367.

Scholfield, C. 1981. Composition of soybean lecithin. J. Am. Oil Chem. Soc. 58:889-892.

Schwarzer, K., and C. A. Adams. 1996. The influence of specific phospholipids as absorption enhancer in animal nutrition. Eur. J. Lipid Sci. Technol. 98:304-308.

Shingfield, K. J., C. K. Reynolds, G. Hervas, J. M. Griinari, A. S. Grandison, and D. E. Beever. 2006. Examination of the persistency of milk fatty acid composition responses to fish oil and sunflower oil in the diet of dairy cows. J. Dairy Sci. 89:714-732.

Urrutia, N. L., and K. J. Harvatine. 2017. Acetate dose-dependently stimulates milk fat synthesis in lactating dairy cows. J. Nutr. 147:763-769.

Weimer, P. J., D. M. Stevenson, and D. R. Mertens. 2010. Shifts in bacterial community composition in the rumen of lactating dairy cows under milk fat-depressing conditions. J. Dairy Sci. 93:265278. 